\title{
Article
}

\section{SwingPingis - An innovative and norm critical physical activity aid for everyone, everywhere}

\author{
Lars Kristén ${ }^{1 *}$ and Mikael Ring²
}

Received: $5^{\text {th }}$ October 2018; Accepted: 11 $1^{\text {th }}$ October 2019; Published: $11^{\text {th }}$ November 2019

\begin{abstract}
Many children with disabilities face the risk of illness by being excluded from physical education. The purpose of this article is to investigate an open collaborative innovation that can contribute to more inclusive elements in physical education, resulting in a better quality of education for children and youths with a disability. The question asked here is whether performative, bodily, geographical, norm critical and collaborative aspects involved in the use of an innovative aid called Swing Table Tennis (SwingPingis), has any impact on teachers' perception of inclusion and well-being for the children using the innovation. The methods used in this study are interviews of children with disabilities and their physical education teachers, combined with participant observations carried out during classes using the tool. The findings indicate children and teachers perceive the tool as a means to an embodied, creative part of collaboration and involvement during the lesson, as well as in the teaching of the subject Physical Education. Children perceived SwingPingis as an opportunity to get motor training and build bodily capacities to perform, which in turn were reported as a feeling of the joy in movement. Teachers emphasize SwingPingis usefulness and accessibility. It is an asset in teaching as well as enabling and complementing other motor training in teaching.
\end{abstract}

Keywords: Children, disability, embodied physical education, norm critical innovation, health technology

\section{Introduction}

Many children with disabilities face the lack of wellbeing as well as being excluded. (Swedish National Institute of Public Health, 2008). The WHO definition of health is 'a state of complete physical, mental and social well-being and not merely an absence of disease or infirmity', which is in accordance with a holistic perspective as well as the idea that health is both multi-dimensional and subjective (World Health Organization, 1947). Nevertheless, the definition by WHO has been developed in the Shanghai Declaration by describing how health literacy plays an important factor in health and well-being (World Health Organization, 2016). Causes related to the lack of well-being and even illness may start early in school. One reason for excluding children with disabilities is the lack of norm critical and inclusive sports equipment in order to reach a common, or lower level of activity where health and well-being effects can be found (Johnson, 2009; Klavina, Jerlinder, Kristén, Hammar, \& Soulie, 2013). The merits of physical activity consist of developed aerobic capacity, improved gross motor skills and a high satisfaction from participating children and their parents (Engström, 2004; Johnson, 2009). In a review article, Verschuren and colleagues (2008) reported different types of exercise programs for cardio-pulmonary function and muscle strength in the limbs of the target group of children with cerebral palsy $(\mathrm{CP})$. These authors believed that it is important to determine the effectiveness of training programs when it comes to increasing daily activity and participation level of children with $\mathrm{CP}$, and increasing their self-awareness and quality of life. Furthermore, a better health quality is achieved through the process of a subject's capacity building by the means of repeated bodily movement. Thus, there is a spatial and embodied will to navigate in space without being dependent on someone else's help to put the SwingPingis ball in motion. As such, the individual produces empowerment and geographical independency (Jonasson, 2014).

Norm critical can broadly be defined as a perspective with which power structures and privileges are made visible so that both those who feel that they belong within norms and those who feel that they belong outside norms can discover how they are limited by such norms (Brade, Engström, Sörensdotter, \& 
Wiktorsson, 2008). Children and young people with disabilities (especially those who have a physical disability), exhibit the poorest health status in Sweden (Swedish National Institute of Public Health, 2008). For children and young people with disabilities, it is important to satisfy their needs of movement and enjoy the experience of movement, recreation and togetherness. This applies to promote the inherent desire for physical activity and health (Shields, Synnot \& Barr, 2012) which many children, with and without disabilities experience from lessons in physical education at school. To participate in school physical education or leisure time sport activities is however not always clear for children with disabilities after taking into account both barriers and facilitators that are connected to the perceptions related to personal, social, environmental and policy or program factors. Furthermore, for many children with disabilities sport and exercise activities could be of even greater importance than for children without disabilities, particularly when it comes to health and wellbeing (Kristén, 2003).

Currently, the knowledge of the importance of play, movement and PA for children and youth with disabilities is a neglected area (Block \& Obrusnikova, 2007). The question asked in this paper is whether performative, bodily, geographical, norm critical and collaborative aspects involved in the use of an innovative aid called Swing Table Tennis (SwingPingis), can have any impact on teachers' perception of inclusion and thus also an assumed well-being for the children using the innovation?

SwingPingis consists of a ping pong ball attached to a string that is mounted on a door frame or any other extension of the room. The ball is hit by an ordinary ping pong racket. The tool is constructed for children with disabilities, since the string makes the ball return on every hit. SwingPingis was used daily in the classroom during periods ranging between 20 and 30 minutes.. The equipment was hung up in a door post or equivalent so that it was available to the students all day long. The pupils, for example, utilized active breaks through the use of SwingPingis. The teachers provided opportunities for the students to exercise daily PA with SwingPingis. SwingPingis was introduced by the researchers and physical education teachers at a physical education lesson. The teachers then used the sports equipment for 3 months in physical education lessons. The students had lessons in physical education on average 2 times a week, of which, one lesson could be in a smaller group of students and another lesson with full class.

The Institute of Public Health (2011) writes in conclusion that the differences between children with and without disabilities are highest in the areas of mental health, bullying, and lifestyles. It is possible to reduce these differences by acting in line with the Education Act (Ministry of Education, 2010) to prevent degrading treatment of children, and thereby improve pupils' physical and mental health. There is also support in primary school curricula for daily PA during the school day. The Swedish National Institute of Public Health (2008) argues that much ill health can be associated with various determining factors such as lack of power, discrimination, and lack of availability. It is possible that a much greater inclusion of people with disabilities is required to deal with well-being and even health problems within this group of people, and it is important to start early in life (Berg Svendby \& Dowling, 2012). Some may refer to in using the lack of resources in supporting children with disabilities, and thus reject support (Vickerman \& Coates, 2009; Jerlinder, 2010). However, under the Education Act (Ministry of Education, 2010), it is stated that a pupil who is in need of special assistance should be given the necessary support. If there are special circumstances, pupils can get their support individually or in a special education group. Pupils should also have the opportunity to influence education. In the new curriculum for primary schools, LGR 11 (The Swedish National Agency for Education, 2011a) it is even stated that teaching should be tailored to meet each pupil's needs and abilities. The curriculum also states that schools should strive to offer PA every day, and that each student should feel connected to a group and feel respected. The curriculum for physical education and health says that pupils should be given opportunities to develop their ability to work together and to respect other people through education.

\section{The relationship between norm critique, repetitive motion and wellbeing}

Relations between repetitive movements and well-being connect the body's own memories and the feeling of being an independent individual. Independent movements are also linked to physical memory and the development of synapses. Keleman (1985) claims that voluntary and repetitive movements create a chain of behaviours in which an accumulation of a critical mass of axons produces an anatomical memory. This anatomical memory helps an individual, from an embodied and emotional view, to inscribe a person's 
subjective view of his or herself in relation to their surroundings. Repeated voluntary measures will strengthen and develop new synaptic connections. Repetition produces feedback based on intense physical experience that will help a person to organise experiences in terms of where, what, and why experiences unfold. Intense physical somatic mobile experiences thus stimulate individual maturity in terms of being a member of society who is more prepared to make a difference in the world. So, when movement and stillness are weaved together in order to produce rhythms, the creation of meaning becomes directly related to a person's experience of being in the world and making a difference. Self-controlled movements of one's body and creative conditions for changing, shaping and challenging one's skills in relation to self-control, thus also alters experience and learning through physical movements. Physical training is thus not a means in itself; it is not even a measure of well-being. Instead, physical capacities promote health and well-being through independence, and thus it is a means for coping with the world and being a complete human being. It is thus important to examine some of the implications of physical capacities by linking together theories of norm critique, physical activity and existentialism, which focuses on people's being in the world through the body, with open collaborative innovative aspects.

The reason for combining disability, play and innovation is that we regard them as forming 'life-worlds' for people. People's life-worlds are structured by these norms and their existence, and give meaning and understanding to the acts they perform in these life-worlds. The needs to be met are often limited to movements within a specific bodily capacity area and within a certain timeframe, but they are not limited to needs such as food, sleep and social interaction; they are existential and woven into a web of creative and negotiated relations with other people and the environment, which are embedded in norms.

Activity is commonly used as a concept that refers to some type of practice, mainly involving user and producer enactments (Hedvall, 2009), for instance families or teachers configuring SwingPingis activities. In order to distinguish different types of activities or practices, the term 'performative' is used here. The concept performative refers to the thinking of the body and "the inter-corporeal conduct of human knowing and doing" (Whatmore, 2002, 4). Performing physical activities involves the reconciliation of self and other, body and identity, norms and threats to norms, materiality and sociality. Performance is thus a constitutive feature of any rhythmical movement in an inter-corporeal context of embodiment, of the shaping of subjectivities, norms and materialities (Crouch, 1999; Deleuze \& Guattari, 1994; Lefebvre, 2004; Wylie, 2002; Thrift \& Dewsbury, 2000). Materialities are included since they have a role as non-human agents who are involved in the creating and sustaining of norms related to physical activities (Carter, Dodsworth, Ruppert \& Watson 2011; Latour \& Hermant, 2009; Murray, 2016; Ring, Kristén \& Klingvall-Arvidsson, 2017). Norms are often oriented towards competitive ideals and identities where materials in a sports centre are seen as complete, and not viewed as being in a process of being constantly made (Carter et al., 2011; Ring et al., 2017).

Performance was earlier synonymous with a measurement of satisfaction, but performance studies inspired by Butler $(1993 ; 1997)$ explain that performances do no unfold in a pre-given discursive field; rather they shape the very texture and contours of the terrain because narratives and all other types of acting that can be related to disability have a distinctive agency - they are acts with consequences (Butler, 1997). Hence, performances may not just involve discourses and discursive formation, they can also engage the whole body in producing effects and consequences (Butler, 1997).

Distinguishing a particular type of activity that carries significant performative characteristics could entail asking questions regarding the relation between physical activity, norms, disability and innovations. For a person to develop emotionally, bodily, linguistically, cognitively and socially, play has important roles (Denham et al., 2010). Play and mobility do not end with childhood. The development of social relations through play continues to be important also for adults who use it to take part in society and to be able to identify and be identified as an independent yet capable member of society. As such, performative and significant practices of play involve the reconfiguration of micro-landscapes and the creative practice of producing conditions for playing with SwingPingis. These performances are part of a collaborative innovation process involving embodied performativety, norms, and materialities.

Non-verbal actions, like play, do not merely reflect the meaning conveyed by moving a body in space; rather they are tools used in the continuous and simultaneous production of meanings performed by people who play. Non-verbal actions of significance are bodily elements that perform bodily enactments, which in 
turn produce playing places of activity, including passive places of stillness, which also performs meaning (for instance resistance, humour, mocking, etc.). When these non-verbal actions are repeated with intention they produce significance and may thus be defined as being performative and producing a place through agency.

Since the production of innovative places involves the performance of significance, norms play an important role. SwingPingis produces significant meaning and creates the place through agents involved in shaping stillness and play. By playing together, by inventing new ways of playing, and by expanding and challenging norms, and the rules and conditions for playing, significance is created on several continuum scales with no visible boundaries, and can thus be defined as an open norm critical collaborative innovation A norm critical and open innovation thus both involves and expands possible places for experience, learning and fun that are produced by families, teachers and players (Baldwin \& von Hippel, 2009).

Since open norm critical innovations are embedded in social relations they also configure and reproduce possible and emergent actions - the play determines what actors can achieve together - it is important that equipment and teaching methods are inclusive. Performances of play can involve creative practices that reduce the significance of disabilities and it may build individual capacities that involve motoric functions, and reduced or loss of sight and hearing, difficulty concentrating, affected and limited perception, influence an individual's capacity to register, recognize and organize everyday impressions and social relations (Keleman, 1985; Sjöberg, 1996, 80). Or, these performances may also do the opposite, which is important because this means that teachers, parents and others have a choice to make a difference.

For instance, with the help of play technology that affords creative adjustments, some of these effects of disabilities can be reduced. Creative work negotiates the configuration of human as well as non-human aspects (Hedvall, 2009, 42-43; Latour, 2003). From a norm critical perspective, creative practices involving embodied play changes people's perceptions and experiences with changing relationships and positions, such as normal or not normal (Deleuze \& Guattari, 1994; Keleman, 1985; Massey, 1994; Serres, 1995). It is, for instance, possible to perform social interaction and play in space and time with the help of the SwingPingis, and in short, experience a good life according to the person's abilities and needs, at the same time as boundaries for what is possible to achieve continuously are being pushed forward (Hurley-Geffner, 1995).

\section{Open norm critical and collaborative innovation and teachers}

Innovations are often associated with technological progress and business practices. However, innovations can also be defined as progress in methods and thinking in terms of individuals involved in development processes with the help of care-givers and teachers. Through this development the capacity is strengthened to develop and learn at the same time as norms are being challenged on daily basis. An open norm critical innovation may thus occur when schools, users and families collaborate on and deal with complexities that produce new ways of thinking in relation to a product or a service (see Cooke \& Eriksson 2011; Hovlin, Anderesson, Hjort \& Ljung, 2011).

The SwingPingis tool is here defined as an open norm critical and collaborative innovation in terms of negotiating a multiplicity of affordances of different use, and the challenging of norms by actors involved in it. The tool re-orients roles and norms from Schumpeter's producer's model in 1934, where it was assumed that the most important innovation came from a producer, to a single-user innovation model and an open collaborative innovation-model, where the role of inventor now is held by consumers rather than producers (Baldwin \& von Hippel, 2009).

As an open norm critical and collaborative innovation, SwingPingis engages actors from families and schools in a challenging, but yet creative and a playful way. An open norm critical and collaborative innovation aspires for inclusion of a wider network of people with disabilities, even care-givers, albeit if their role is shown to be somewhat invisible and downplayed (Larsson \& Holmström, 2007). Many studies have shown the importance of emotional engagement in care-givers, and that mothers and fathers value their disabled children despite their challenges (Esdaile, 2004; 2009; Fialka, 2004; Larskia-Smirnova, 1999; Larsson \& Holmström, 2007). This study confirms the importance of involving teachers, care-givers and families; the interviews indicate the significance of the reciprocal and emotional dimensions of co-producing and coconstructing the ways of using SwingPingis in school and at home. 


\section{Methods}

This study combines two types of methods: phenomenography and ethnomethodology. Phenomenographic approaches are used when it comes to issues related to the understanding of learning in different educational environments, especially when interviewing teachers and children (Larsson \& Holmström, 2007; Marton \& Booth, 1997: Sjöström \& Dahlgren, 2002). Phenomenography builds on an interest in describing how people conceive phenomena in, or aspects of, their surroundings using two different levels of description: the first-order and the second-order perspective (Alexandersson, 1994). Phenomenographic analysis leads to conceptual understanding by formulating categories of description (Barnard, McCoscer \& Gerber, 1999; Tight 2016). The intention behind phenomenographic data analysis is to identify the meaning content of conceptions and to formulate descriptive categories. In the phenomenographic study, there are no predetermined categories (Alexandersson, 1994; Larsson \& Holmström, 2007; Tight, 2016).

This study also used participant observations that can be placed within the tradition of phenomenology, ethnomethodology, and wider qualitative methods (DeLyser, Herbert, Aitken, Crang, \& McDowell, 2010; Garfinkel, 1967). The fundamental question within ethnomethodology is to observe based on the question, What is going on here, who determines what is possible to do and what is not?. Observations were also participatory, meaning the researcher took part in and played with the children while asking questions. As such, the researchers represents the reality observed and questions asked during the sessions are produced by the research, and in which social actions are embedded in the place for co-practicing play with the SwingPingis tool. The questions asked during these sessions were more directed towards the game itself and how to manage, be creative and encouraging to play, such as, What do you do if you don't have a table tennis racket? This means a different strand from the ontological and epistemological assumption that the researcher is representing the reality by collecting data (DeLyser et al., 2010).

Three compulsory schools from a town in western Sweden were selected as research sites in this study. Qualitative interviews were conducted with three children with disabilities and their two physical education teachers. Three compulsory school age students with moderate physical disabilities and mild cognitive impairments were target students, further referred in text with the fictive names Karin, Anton and Erik and two compulsory school physical education teachers further referred in text with fictive names Krister and Pavel. In addition, three participant observations were conducted during class. Both interviews and participant observations lasted for about one hour each. An information letter, including consent for the study, was sent out to the children, parents and schools.

The interviews were conducted individually with three children with disabilities and two physical education teachers. The interviews were separate from the observations. The interviews with physical education teachers were conducted separately at the teacher's room at each school after the end of the school day. The important questions concerned expectations and experiences, as well as experience and knowledge of SwingPingis. Also, questions were targeted regarding the usefulness and importance of the swing table tennis from a general usability point of view. The teachers were being asked about the meaning of Swingpingis for the children when using the tool, thus relating to a phenomenographic analysis, by reflecting upon abilities, inclusion and well-being, the role that the tool played for stimulating PA, and how the tool could be improved in an ongoing innovation process. The interviews with children involved the feelings and anticipations before and after the session with Swingpingis, such as: "what do you expect will happen?", "how did it feel to use the tool", also relating to a phenomenographic analysis.

The researchers transcribed the interviews to text in connection with the interview in order to minimise the risk of misinterpretation of facts in the interview material. An interview guide was used with non-leading semi-structured questions based on Kvale \& Brinkman (2009). The researchers transcribed the interviews soon after they were conducted, thereby reducing the risk of misunderstandings and ensuring a high level of conscientiousness and trustworthiness. In addition, as the researchers carried out the analysis together and negotiated consensus, they diligently sought to achieve a high level of conscientiousness. In phenomenographic studies it is usual to rely on the quotations in order to develop descriptive categories. At the same time, the quotations have the function of enriching and concretizing the meaning of the categories. Written consent was made with children, parents and teachers at schools where studies were conducted. All of them accepted participation and that the material would be used for publishing in scientific journals. Since 
this was a pre-study, no ethical approval was sought. Ethical review has been approved for similar studies by the Swedish Ethical Review Authority, Lund University (Etik:H15 2015/851).

\section{Results and analysis}

The interview material is presented in the form of quotes from the talks, where space for vivid and rich response examples are given. Interviews made in pre-measurement revealed excitement and expectations from the pupils. Results from the study are categorized in four performative themes - preconceptions, internalizing it within a sports framework, lifestyle change, and collaborative innovative practice.

\section{Theme one - preconceptions}

Children were full of anticipation and looked forward to trying the swingpingis. For instance, to the question How do you feel before you to try the swingpingis? Answers varied: Karin: "We are excited to try it."; Anton: "Yeah, it's great."; Erik: "Exciting".

Expectations were based on consequences and effects of the tool from examining it closely. It was quickly concluded that the cause and effect from hitting the ball would produce a different one compared to traditional ping pong, yet with an interesting result. For instance, to the question What do you think will happen when you play swingpingis? Answers varied: Karin: "It is well to turn it on and then the well back, or so, back and forth"; Anton: "Do the front and back. Turns on the door frame and then back. Against me"; Erik: "I'm going to hit the ball, many times. Sometimes I will not hit".

The children related the responses to a PA in which the body is in motion and the ability to hit is tested. The importance of eye-hand motor function can be read into the answers. Anticipating repetitive movements and well-being is here seen to connect the body's own memories and the feeling of being these individuals. It is almost possible to foresee movements that will help, not only to perhaps develop synapses, but also to challenge norms regarding who may or may not participate in sports (Keleman, 1985).

\section{Theme two - internalizing it within a sports framework}

In order to fulfill the requirements of curricula, children in school need to be offered the opportunity to move and to try different kinds of sport. According to Swedish curriculum for Special School for children with disabilities: "Education in health and sports aims at developing versatile moving abilities and interests for being physically active /.../. Through the education, pupils will be able to try different types of physical activities (The Swedish National Agency for Education, 2011b) Curriculum for Special School, p. 43). According to Swedish curriculum for compulsory school, preschool classes and recreation centres: "Creative activities and games are essential components of active learning. In the early years of schooling, play in particular is of great importance in helping pupils to acquire knowledge. The school should strive to provide all pupils with daily PA within the framework of the entire school day." (Swedish National Agency for Education, 2011a, p. 9).

The children made comparisons between SwingPingis and ordinary table tennis when describing its characteristics as a sport. For instance, to the question What do you feel about swingpingis as a sport? The answers varied: Karin: "It is difficult to know when you have not tried yet". Anton: "It's mostly running and most jumping and high jump, and most all of this. Different sport". Erik: "It's something for the arms. Moving them a lot and stuff like that".

Even though the children found it hard to frame SwingPingis as a sport, before trying it out, they still agreed on the tool as something connected with sport, among other physical activities in lessons in physical education. This means that the image of a "self "capable of using the body as a tool for changing the world has to be considered in relation to these children's positions, being disabled and excluded from physical education. When Erik says he anticipates moving his arms, it means that not all activities he is involved in normally may not present such challenges. It means projecting and preparing for a different image to what is possible with these arms and with this tool. They are prepared for the performance of bodily actions that relate to other types of sports in terms of muscle pain as a result from tough training, and thus SwingPingis is compared to the same complexity and advanced level as any other sport. As SwingPingis transcends to the 
same level of advancement it also produces images of a "self" capable of using the body as a tool for changing the world.

\section{Theme three - Reconfiguring self and identity in relation to lifestyle changes}

SwingPingis orients focus on playing a game, but which has wider implications for all actors involved in it. It involves the collaborative negotiation of how a technology can be adjusted in order to reconfigure human as well as non-human relations (Hedvall, 2009, 42-43; Latour, 2003). The embodied play may change how a person perceives and experiences categories of normal, and challenge the normal (Deleuze \& Guattari, 1994; Keleman, 1985; Massey, 1994; Serres, 1996). In some cases, as seen below, SwingPingis helps a person to experience a good life according to the person's abilities and needs, and at the same time boundaries for what it is possible to achieve are continuously being pushed forward (Hurley-Geffner, 1995). For instance, to the question How do you think swingpingis may affect you? Karin: "I do not know. It is possible that there is a way for me to move"; Anton: "Sometimes it's a pain, sometimes not so tough. I always hit the right hand, sometimes I turn and turn". Erik: "Don't know, something you work out your arms, you hit." As well as in the question How do you feel before you try the swingpingis? Karin: "I think it is, it feels okay. Good "; Anton: "Swingpingis, I play all the time. I cannot help it. It feels good. I thought I would have such a home. I can learn to play tennis". Another related question What do you feel for swingpingis as a sport? Karin: "I think. I do not feel as if it's a real sport for me. Because I feel that I want to move my whole body"; Anton: "I feel all the time. I know that. It seems that, what can you say, I feel that I train up the entire arm and get a little soft arms"; Erik: "Everything is a sport. This kind of training".

Children express the playing of swing table tennis as a positive act for them. It is something that mimics traditional table tennis and creates the joy of movement. SwingPingis is something that can be mastered, but it also extends doing in other parts of life worlds. When Anton says that he can learn to play tennis, he also visualizes further progression and beyond SwingPingis; it is almost like real tennis. The repeated voluntary movements will thus do more than strengthen and develop new synaptic connections (Keleman, 1985); it will also produce an anatomical memory with the sense of the world with the help of the shed thus inscribes a person's subjective view of him or herself. This subjective self-view helps a person to organize and reorganize experiences framed by unskilled to skilled capacities. Repeated and self-controlled movements shape both a progression in a person's ability to view themselves as independent and mature human beings, being well because they can cope with their world, as well as a physical condition to continue doing so. For instance, to the question What happens when you play swingpingis? Karin: "Maybe I become stronger in my hand."; Anton: "Yes, I see sometimes. Sometimes I miss and sometimes I meet. I hit so hard. Glasses and all this stuff. "; Erik: "Touching on the body. Sometimes the hand and sometimes you have to move your legs".

After they had tested the tool it was concluded that the children's views differ in the perception of moving the whole body. Throughout, there is a positive feeling for swingpingis and activity seems inspiring. The children confided both motor and health aspects of the swingpingis training, and it seemed to be a natural part of the lesson content (Klavina et al., 2013). Children convey different perspectives on changes in life situation; there are expressions of the use of swingpingis outside of school hours, and that it affects the overall lesson in physical education positively, but also that it does not affect it at all (Berg \& Dowling, 2012).

\section{Theme four - open collaborative and norm critical innovative practice}

SwingPingis is here defined as an open collaborative innovation in terms of negotiating a multiplicity of affordances of different use by actors involved in it. The construction of the tool produces spaces of collaborative creativity by being open at the same time as it is preconceived as a ping pong playing device. Its innovative aspects are produced through constant negotiation by actors such as teachers, care-givers, and schools - who collaboratively or competitively co-construct its capacities as a tool, a prolonged bodily extension that produces a performative effect. The driving force for engaging are reciprocal and emotional values of viewing a person feeling well and being capable of coping with the world. However, its implications go beyond that by challenging norms about who can do sports and how it may be done in order to be inclusive by focusing more on experiences of acting, rather than on results from activities.

Participant observations of Anton showed that he thought it was fun to play SwingPingis. He was engaged and wanted to show what he could do and that he mastered the technology. For Anton, the situation 
was such that he very quickly understood how to use the tool, and the fact that he mastered it so quickly made him a little bored after a while. When he felt he had mastered the implement fully and met the ball every time he stood leaning against the doorpost. When he discovered that this meant that he managed to hit the ball every time, he started to close his eyes and hit the ball. He succeeded to calculate the ball's trajectory and speed relative to the racket, and could thus manage to hit the ball with accuracy every time. This lasted only a short while; the teacher told him that he could use his hands instead of a racket to test if it was as easy. He concentrated on this new challenge and succeeded after a short while to conquer it. The teacher asked him to change hands, to reach another level of difficulty, which was a bit difficult for him with his left hand.

Anton and his teacher tried to set up the gear in places other than in a doorway to find new ways to challenge his abilities. Together, the researcher and physical education teacher enabled him to use other parts of his body to hit the ball with. Accidentally, the ball hit his head and then he began to try to hit the ball with his head and we started to focus on that on purpose. After mastering that, he wanted to try to kick the ball with his feet, but the tool did not have long enough string, so he went on to vary the hit with his hand and nod with the glasses on the ball. Anton and his teachers also had thoughts about whether they could involve more players at the same time if they attached the device into one of the bars in the gym. In that way they could have a collaborative game with several players.

SwingPingis is quite open, affording different uses and creating opportunities to explore the relation between the space between the ball and a player. Furthermore, it opens up affordances to explore the performative relation between the teacher and the players in relation to the space between them and the ball. The collaborative and creative discussion concerns incremental innovations that give meaning and new ways of using the device (Baldwin \& von Hippel, 2009). This collaborative and creative element engages in such ways that it involves all participants on the same level of understanding. It also means that all participants are rewarded through their input in the game. The teacher wants the pupil to be motivated to engage physically, and the pupil wants to master the game in order to be measured according to his or her capacities as a player, and as a human being who can learn. For instance, to the question What is critical for you to want to have a tool in physical education and health lessons? The teachers responded:

Krister: "It's supposed to be something that makes it easier for students, and that what arouses the desire to move. Yes, then the cost may not be too high either"

Pavel: "... as I travel between schools, how easy is it to lift it in and out of the car. I mean it should not be too hard work to take it with me... and then, I can feel it must be something that we spoke about before, that you have something that helps the pupils, which is not possible in any other way...it is about keeping the ball alive at the right level with the feeling that encourages...yes, finding the right way at the right time when it comes to hitting the ball correctly."

The teachers emphasise factors such as simplicity, not difficult to transport between lessons, as well as the economic aspect. The common goal with the collaborative work is a playful way of producing situated meaning and learning that, in turn, produces performances of embodied existential and physical capacities (Crouch, 1999; Deleuze \& Guattari, 1994; Butler, 1993; 1997; Lefebvre, 2004, 78; Wylie, 2002; Thrift \& Dewsbury, 2000). The driving motivating force creates meaning and norm critical features, pleasure, commitment, and repetitive bodily movement.

The teachers raise the question of health aspects as well as motor development opportunities and explain the elements in bodily movements in temporal and spatial terms, as timing and force. These children often have only two positions - either full power or no power at all, and not always in the right timing. The device thus helps these children to develop esteem in relation to eye-hand motor skills. As such, it also contributes to existential and geographical independence on an individual level. For instance, to the question What do you think it means for the children to use the device swingpingis if we focus on their health and motor skills? The teachers responded;

Krister: "Motor. Yes, I taught this course so that students, that something happens. That it is a novelty, something fun, movement and that confidence, that they can, you might be able to learn the bounce 10 times. That they are growing. Thus, self-confidence, self-esteem, cognitive...". 
Pavel: "Yes. Well, I have seen a small movie clip /.../ and I've also had time to try it a little bit. But it is precisely this that I said before, about when I use the racket and ball to practice eye-hand coordination exercise. And it does look like it could be a suitable aid for some children, well, that the ball comes back /.../ Then we have not used so much, but I have seen it in action a little bit. That it's maybe not quite as simple as it looks on film".

As well as in the question What does swingpingis mean for a teacher in physical education and health?

Krister: "It is also as we have said before, it's an aid to train racket sports, or I suppose table tennis, and it makes it easier for students who have poor motor skills, who find it difficult to hit the ball, play games, have difficulty to play table tennis. It's good. A great aid".

Pavel: "I can imagine, now that you put it that way, of having two or three of them here in action simultaneously. And then you have three students who can play by themselves, or practice while the teachers may be able to spend time helping somebody else. Possibly around the same theme. Ball, racket and eye-hand. But certainly a tool in such a situation /.../ I think I can, after many years of experience, say that I can see that, and I feel it sometimes, that I do not have enough simple exercises when it comes to hitting a ball with a racket. For example, if you're going to do serve in badminton, it can be difficult. But here, I think we can find more kids who feel they are capable of hitting a ball with a racket".

The teachers express great satisfaction with the aid and its uses. The children are considered the winners and the teaching situation becomes easier. The teaching experience, in general, can be considered to be moving in a favourable direction.

\section{Discussion}

This study shows the importance of adapted embodied PA that is repeated in a social and collaborative context. It reveals the elements of collaborative incremental innovations and their driving forces for individual and group participation (Baldwin \& von Hippel, 2009). It also shows that repeated voluntary embodied movements are crucial for creating an anatomical memory Keleman (1985), which in turn also builds an individual's capacity. The performance of capacity building through rhythmical movement in an intercorporeal context of embodiment, and of the shaping of subjectivities, not only create geographical independence, it also builds an individual's capacity to challenge norms and materialities, and thus spur further achievements (Jonasson, 2014; Serres, 1995).

The study shows the importance of adult overview, but also as challenging norms, demanding learning and creativity, and for creating inclusion. The results suggest that children and teachers perceive SwingPingis as a means to a creative part in the lesson and the teaching of Physical Education. Children perceive SwingPingis as an opportunity to get motor training and feel the joy of movement. Through this, the children express that SwingPingis is an inclusive sports equipment that strengthens the opportunities for participation in the school subject of physical education (Shields et al., 2012; Klavina et al., 2013). The children also reason about various health benefits. It can also result in a higher degree of PA and movement for the children and stimulate inclusion in activities with other children through the tool's norm breaking character (Berg Svendby \& Dowling, 2012; Ring et al. 2017). Teachers emphasize its usefulness and accessibility. It is an asset in teaching as well as enabling and complementing other motor training in teaching. Furthermore, it stimulates the health of children.

\section{Perspective}

This study shows the relationship between norm critical innovation and the development of social, relational, emotional, existential and physical abilities. Findings clearly indicated that people with disabilities developed as complete people; SwingPingis contributed greatly to that given development.

The repetitiveness in SwingPingis has advantages and disadvantages. It's easy to "get into" the way the equipment can be used and it is simple and predictable in terms of how the body is used to hit the ball. It is 
also an advantage that physical education classes are easy to organize and the tool is easy to set up. A disadvantage is that the challenges can be easily lost if:

- there is a need of a coaching person who can provide suggestions on how the exercises can be varied

- the device is designed as a pure exercise; it also needs to be a meaning-making tools or

- there is no guidance or direction to the way the equipment can be varied in use.

The merging of phenomenographic and ethnomethodological approaches is challenging from an epistemological perspective. However, in this study the two methods were necessary to combine in order to triangulate the embodied, material, and experienced; and the non-verbal and the verbal; together with the theoretical framework. However, it must be concluded that more research is needed in order to make justice of these two methods in combination.

The practical implications from this study is that the inventor of the product have been successful in commercializing the product on a market. It has also been promoted at the World Championship of table tennis in Halmstad, 2018.

\section{Author affiliations:}

1 PhD. School of Health and Welfare, Halmstad University, Sweden; lars.kristen@hh.se

2 PhD. Unit for Human Geography, Department of Economy and Society. School of Business, Economics and Law, University of Gothenburg, Sweden; mikael.ring@geography.gu.se

* Correspondence: lars.kristen@hh.se; Tel.: +4635167215

Funding: This research received no external funding.

Acknowledgements: The authors would like to acknowledge the EUJAPA editorial team for correcting large chunks of the language in the manuscript

Conflicts of Interest: The authors declare no conflict of interest. There is no relationship between the inventor of the game and the researchers.

\section{References}

Alexandersson, M. (1994). Den fenomenografiska forskningsansatsens fokus. (Focus of the phenomenographic research approach). In B. Starrin and G. Svensson (Eds.), Kvalitativ metod och vetenskapsteori (The qualitative method and theory of science) (pp. 111-136). Lund: Studentlitteratur.

Baldwin, C. \& Von Hippel, E. (2009). Modelling a Paradigm Shift: From Producer Innovation to User and Open Collaborative Innovation. MIT School of Management Working Paper 4764-09.

Barnard, A., McCoscer, H., \& Gerber, R. (1999). Phenomenography: A qualitative research approach for exploring understanding in health care. Qualitative Health Research, 9(2), 212-226. doi:10.1177/104973299129121794

Berg Svendby, E., \& Dowling, F. (2012). Negotiating the discursive spaces of inclusive education: narratives of experience from contemporary Physical Education. Scandinavian Journal of Disability Research, 15(4), 361378. doi:10.1080/15017419.2012.735200

Block, M.E., \& Obrusnikova, I. (2007). Inclusion in physical education: A review of the literature from 19952005. Adapted Physical Activity Quarterly, 24, 103-124. doi:10.1123/apaq.24.2.103

Brade, L., Engström, C., Sörensdotter, R., \& Wiktorsson, P., (2008). I normens öga [In the eye of the norm]. Stockholm: Friends.

Butler, J. (1993). Bodies that matter: on the discursive limits of sex. New York: Routledge.

Butler, J. (1997). Excitable speech: A politics of the performative. Psychology Press, New York \& London

Carter, S., Dodsworth, F., Ruppert, E., \& Watson, S. (2011). Thinking cities through objects. (Working Paper No. 96). CRESC, Open University. Retrieved from http://research.gold.ac.uk/7986/1/wp\%2096.pdf

Cooke, P., \& \& A. Eriksson, (2011). White spaces innovation in Sweden - Innovation policy for exploring the adjacent possible. Vinnova Report VR 2011:10. VINNOVA - Verket för Innovationssystem/Swedish Governmental Agency for Innovation System.

Crouch, D. (1999). Leisure/tourism geographies: practices and geographical knowledge. London: Routledge.

Deleuze, G., \& Guattari, F. (1994). What is philosophy? New York: Columbia University Press. 
DeLyser, D. Herbert, S. Aitken, S. C. Crang, M., \& L. McDowell. (2010). The Sage Handbook of Qualitative Geography. (Eds.). Part 1 Openings: Introduction. (pp. 21-24). London: Sage.

Denham, S., Warren, H., von Salisch, M., Benga, O., Chin, J. C., \& Geangu, E. (2010). Emotions and social development in childhood. In: The Handbook of Childhood Social Development, Second Edition (Eds.) P. K. Smith and C. H. Hart. Wiley-Blackwell, Oxford, UK. doi: 10.1002/9781444390933.ch22

Engström, L-M. (2004). Barns och ungdomars idrottsvanor i förändring [Children and youth sport habits in change] Svensk idrottsforskning [Swedish sport research], 4, 1-6.

Esdaile, S. A. (2004). Toys for shade and the mother child co-occupation of play. In: S. A. Esdaile, \& J. A. Olson. (Eds.), Mothering occupations. Challenge, agency and participation, 95-114. Philadelphia, PA: F.A. Davis.

Esdaile, S. A. (2009). Valuing difference: caregiving by mothers of children with disabilities. Occupational Therapy International, 16(2), 122-133, doi: 10.1002/oti.274

Fialka, J. (2004). Advice to professionals who must conference cases. In: S. A. Esdaile, \& J. A. Olson, (Eds.), Mothering Occupations. Challenge, Agency and Participation (pp. 391-392). Philadelphia, PA: F.A. Davis.

Hedvall, P. O. (2009). Aktivitetsdiamanten: modellering av en vidareutvecklad tillgänglighet [The activity diamond: modelling of a developed accessability]. Certec-Institutionen för designvetenskaper [Certecinstitution for design science]. LTH: Lund University.

Hovlin, K. Andersson, S., Hjort, M. \& Ljung, A. (2011). Tjänsteinnovationer i offentlig sektor - Behov av forskningsbaserad kunskap och kompetens. Vinnova Report VR 2011:12 [The Swedish Agency for Innovation]. Stockholm: Governo.

Hurley-Geffner, C. M. (1995). Friendships between children with and without developmental disabilities. In R. L. Koegel \& L. K. Koegel (Eds.), Teaching children with autism (pp. 105-125). Baltimore, MD: Paul H. Brookes.

Institute of Public Health. (2011). Redovisning av regeringsuppdraget om delmål m.m. inom ramen för - En strategi för genomförande av funktionshinderpolitiken 2011-2016. [Recognition of the government commission on milestones, etc. within the framework of the Strategy for implementing disability policy 2011-2016]. Östersund: Swedish National Institute of Public Health.

Jerlinder, K. (2010). Social rättvisa i inkluderande idrottsundervisning för elever med rörelsehinder : en utopi? [Social justice in inclusive sports education for pupils with disability: utopia?] (PhD dissertation). Örebro universitet, Örebro.

Johnson, C. (2009). The benefits of physical activity for youth with developmental disabilities: A systematic review. American Journal of Health Promotion, 23(3), 157-168.

Jonasson, M. (2013). The AKKA-board - performing mobility, disability and innovation. Disability E Society, 29(3), 477-490. doi:10.1080/09687599.2013.823079

Keleman, S. (1985). Emotional Anatomy. Berkeley, CA: Centerpress.

Klavina, A., Jerlinder, K., Kristén, L., Hammar, L., \& Soulie, T. (2013). Cooperative oriented learning in inclusive physical education. European Journal of Special Needs Education, 29(2), 119-134. doi:10.1080/08856257.2013.859818

Kristén, L. (2003). Possibilities offered by interventional sports programmes to children and adolescents with physical disabilities; an explorative and evaluative study. Department of Teacher Education, Centre for Research in Teaching and Learning (doctoral thesis). Luleå: University of Technology, Luleå.

Kvale, S., \& Brinkman, S. (2009). Den kvalitativa forskningsintervjun [Qualitative research]. Lund: Studentlitteratur.

Larskia-Smirnova, E. (1999). 'What the future will bring I do not know': mothering children with disabilities in Russia and the politics of exclusion. Frontiers: A Journal for Women's Studies, 20, 68-86. doi: $10.2307 / 3347014$

Larsson, J., \& Holmström, I. (2007). Phenomenographic or phenomenological analysis: does it matter? Examples from a study on anaesthesiologists' work. International Journal of Qualitative Studies on Health and Well-being, 2, 55-64. doi:10.3402/qhw.v2i1.4945

Latour, B. (2003). Why has critique run out of steam? From matters of fact to matters of concern. Critical Inquiry, 30(2), 225-248. doi:10.1086/421123 
Latour, B., \& Hermant, E. (2009). Paris: Invisible city. Retrieved from http://www.brunolatour.fr/virtual/index.html

Lefevbre, H. (2004). Rhythm analysis. Space, time and everyday life. London: Continuum.

Marton, F. (1992). Phenomenography and "the art of teaching all things to all men". Qualitative Studies in Education 5, 253-267. doi:10.1080/0951839920050305

Marton, F. \& Booth, S. (1997). Learning and awareness. Mahwah, New Jersey: Lawrence Erlbaum Associates, Publishers.

Massey, D. B. (1994). Space, place, and gender. Minneapolis: University of Minnesota Press.

Ministry of Education (2010). Skollag (2010:800) [Education Act (2010: 800)]. Stockholm: Fritzes.

Murray, S. (2016). Somatechnics: Queering the technologisation of bodies. Abingdon: Routledge.

Ring, M., Kristén, L., \& Klingvall-Arvidsson, B. (2017). Norms and materialities in physical education and health - "I feel that I cannot contribute enough in sport." Sport, Education and Society, 24(4), 349-360. doi:10.1080/13573322.2017.1394837

Serres, M. (1995). Genesis. Ann Arbor: The University of Michigan Press.

Shields, N., Synnot, A. J., \& Barr, M. (2011). Percieved barriers and facilitators to physical activity for children with disability: a systematic review. British Journal of Sports Medicine, 46, 989-99. doi:10.1136/bjsports-2011090236

Sjöberg, M. (1996). Ung med funktionshinder [Young with disability]. Stockholm: Liber utbildning.

Sjöström, B., \& Dahlgren, L.O. (2002). Applying phenomenography in nursing research. Journal of Advanced Nursing, 40(3), 339-345. doi:10.1046/j.1365-2648.2002.02375

Swedish National Institute of Public Health. (2008). Onödig ohälsa [Unnecessary ill health]. Östersund: Edita Västerås.

The Swedish National Agency for Education. (2011a). Läroplan för grundskolan, förskoleklassen och fritidshemmet 2011 [Curriculum for the compulsory school, preschool class and the recreation centre, 2011]. Stockholm: Skolverket.

The Swedish National Agency for Education. (2011b). Läroplanen för Grundsärskolan (SKOLFS 2010:255). [Curriculum for Special School]. Stockholm: Skolverket.

Thrift, N., \& Dewsbury, J. (2000). Dead geographies-and how to make them live. Environment and Planning D, 18, 411-432. doi:10.1068/d1804ed

Tight, M. (2016). Phenomenography: the development and application of an innovative research design in higher education research, International Journal of Social Research Methodology, 19(3), 319-338. doi:10.1080/13645579.2015.1010284

Verschuren, O., Ketelaar, M., Takken, T., Helders, P. J. M., \& Gorter, J. W. (2008). Exercise Programs for children with cerebral palsy. American Journal of Physical Medicine E Rehabilitation, 87(5), 404-417. doi:10.1097/phm.0b013e31815b2675

Vickerman, P., \& Coates, J-K. (2009). Trainee and recently qualified physical education teachers' perspectives on including children with special educational needs. Physical Education and Sport Pedagogy, 14(2), 137-153. doi: 10.1080/17408980802400502

Whatmore, S. (2002). Hybrid geographies: natures, cultures, spaces. London: Sage.

World Health Organization. (1947). Construction of the World Health Organization, 29-43.

World Health Organization. (2016). Shanghai Declaration on Health Promotion. Retrieved from https://www.who.int/healthpromotion/conferences/9gchp/shanghai-declaration/en/

Wylie, J. (2002). An essay on ascending Glastonbury Tor. Geoforum, 32, 441-54. doi:10.1016/S00167185(02)00033-7

(C) 2019 by the authors. Submitted for possible open access publication under the terms and conditions of the Creative Commons Attribution (CC BY) license (http://creativecommons.org/licenses/by/4.0/). 